\title{
Financiamento Habitacional no Campo: a sustentabilidade como problemática no desenvolvimento de edificações rurais. Caso do Distrito Federal.
}

\author{
THEODORO, Julia Huff ${ }^{1}$ \\ MARAVALHAS, Raul ${ }^{2}$ \\ ANDRADE, Liza Maria de Souza ${ }^{3}$ \\ SILVA, Caio Frederico ${ }^{4}$
}

1Centro de Ação Social em Arquitetura Sustentável - CASAS, Faculdade de Arquitetura e Urbanismo - FAU , Universidade de Brasília UnB, Distrito Federal, Brasil. huff.arq@gmail.com

2CASAS / FAU / UnB, Distrito Federal, Brasil. raulmaravalhas@gmail.com 3CASAS / FAU / UnB, Distrito Federal, Brasil. lizamsa@gmail.com

${ }^{4}$ CASAS / FAU / UnB, Distrito Federal, Brasil. caiosilva@unb.br

\begin{abstract}
Resumo
O presente trabalho busca apresentar o atual cenário de inter-relação entre as políticas públicas brasileiras de financiamento habitacional no campo e a realidade de implementação de construções mais sustentáveis em assentamentos rurais em formação no contexto do Distrito Federal do Brasil. A pesquisa é fruto da colaboração entre comunidades rurais assentadas na região do Distrito Federal e a Faculdade de Arquitetura da Universidade de Brasília - FAU UnB em parceria com o escritório modelo CASAS Centro de Ação Social em Arquitetura Sustentável. Partindo de resultados de pesquisa de campo, bem como de referenciais técnicos e metodológicos, o artigo visa elucidar e analisar questões relativas às dificuldades encontradas pelas comunidades rurais no emprego de ecoprodutos e ecotécnicas na construção e financiamento de suas unidades habitacionais, destacando principalmente os processos burocráticos e técnicos envolvidos na aprovação de técnicas e materiais inovadores dentro do âmbito do Programa Minha Casa Minha Vida PMCMV.
\end{abstract}

Palavras-Chave: Programa Minha Casa Minha Vida; Programa Nacional de Habitação Rural; Assentamentos rurais; Ecotécnicas; Ecoprodutos.

\begin{abstract}
This paper presents the current scenario of inter-relationship between the Brazilian public policies regarding rural housing financing and the reality of implementation of more sustainable buildings among rural settlements in formation in the national territory. This research results from the collaboration between rural communities settled in the Federal District and the Faculty of Architecture and Urbanism of University of Brasilia, in partnership with the Center of Social Action in Sustainable Architecture - CASAS student's office. Based on field research results as well as on technical and methodological references, this paper seeks to elucidate and analyze topics relating to the difficulties found by rural communities in the use of ecoproducts and ecotechniques in the construction of their housing units, specifically emphasizing the bureaucratic and technical processes involved on the approval of innovative techniques and materials within the scope of the Brazilian governmental housing finance entitled Programa Minha Casa Minha Vida - PMCMV.
\end{abstract}

Key-Words: Programa Minha Casa Minha Vida; Programa Nacional de Habitação Rural; Rural settlements; Ecotechniques; Ecoproducts. 


\section{Introdução}

Pensamos em uma política com programas, projetos e metas. Não queremos ser os que parecem que fazem. Pensamos em uma política que provoca e cumpre sua razão essencial: muda consciências, estimula participação, abre espaço. Faz da democracia não um jogo de aparências, mas o resultado das participações sociais; faz do povo o sujeito do seu destino [...] (KOUTZII, 1991).

O presente artigo é desenvolvido como parte do projeto de extensão da Faculdade de Arquitetura e Urbanismo da Universidade de Brasília (FAU-UnB) intitulado "Ecoagrovila Renascer: Projeto de urbanização sustentável em Planaltina"1, em parceria com o Centro de Ação Social em Arquitetura Sustentável CASAS, o Escritório Modelo em Arquitetura e Urbanismo da FAU-UnB. Em tempos onde os processos participativos de projetação em arquitetura e urbanismo ${ }^{2}$ e a função social dos profissionais de arquitetura $^{3}$ apresentam-se como termos coadjuvantes nos programas de ensino de graduação, a investigação acerca das políticas públicas de habitação de interesse social no campo (sobre a qual se debruça o presente trabalho) foi desenvolvida inicialmente na FAU-UnB a partir de iniciativa independente do CASAS, que no ano de 2013 entrou em contato com a Comunidade Renascer, formada por famílias participantes do Movimento de Apoio aos Trabalhadores Rurais (MATR) no Distrito Federal.

A Comunidade Renascer, pré-assentada desde

${ }^{1}$ Projeto em andamento homologado pelo edital PROEXT 2015 MEC/SESu.

${ }^{2}$ Barone e Dobry (2004, p. 18) definem os processos participativos de projeto em Arquitetura e Urbanismo como sendo "uma forma de enfrentar a dimensão social e política dos projetos de interesse coletivo, fazendo valer a opinião e o desejo dos usuários, com o fim de garantir maior cidadania e democracia na concepção dos espaços urbanos".

3"Exige-se do arquiteto e urbanista que o mesmo se debruce sobre a sua cidade, compromissado com sua forma, seu conteúdo, [...] que encare a sua tarefa de projetar e reorganizar seus espaços com responsabilidade social, mais que individual" (GOUVÊA, 2004).
2009 pelo INCRA ${ }^{4}$ em uma área de 116 ha localizada dentro da Fazenda Sálvia - de propriedade da Secretaria de Patrimônio da União (SPU) do Ministério do Planejamento e Gestão, na região administrativa de Planaltina, no Distrito Federal -, recorreu ao CASAS no desejo de promover, na área ocupada, a realização de projetos urbanísticos e arquitetônicos condizentes com o sonho das famílias participantes: o de tornar o Renascer uma ecoagrovila. O desafio de ajudar a Comunidade Renascer levou o CASAS a conduzir, no primeiro e segundo semestres do ano de 2014, uma disciplina dentro do curso de graduação da FAU-UnB denominada Prática de Escritório Modelo de Arquitetura e Urbanismo PEMAU.

Nos últimos meses de 2014, o Renascer enfrentou uma conjuntura de disputas políticas internas relativas à divisão de terras o que prejudicou o grupo da FAU-UnB de prosseguir com suas atividades direcionadas ao auxílio técnico em apoio dos interesses da comunidade; apesar de ser atualmente formada por 120 famílias, 80 delas ocupando a área destinada ao Renascer, a Comunidade, por exigência do INCRA, deve reduzir seu número de grupos familiares a no máximo 40, para garantir a permissão de ocupação da terra ${ }^{5}$.

Apesar deste entrave político e das barreiras burocráticas enfrentadas pelo grupo acadêmico no processo de projeto, a experiência com a Comunidade Renascer conduziu os integrantes de PEMAU, do CASAS e do Projeto de Extensão a um universo de pesquisa muito mais abrangente - que envolve os processos burocráticos de divisão de terras destinadas a assentamentos rurais (destaca-se neste cenário o crucial papel do INCRA) e de financiamento a unidades habitacionais de interesse social no campo pelo do Programa Nacional de Habitação Rural (PNHR), dentro do Programa Minha Casa Minha Vida (PMCMV), e sua

\footnotetext{
4 Instituto Nacional de Colonização e Reforma Agrária, instituído pelo Decreto no 1.110 de 9 de julho de 1970. 5As ocupações rurais no Distrito Federal devem atender ao módulo rural mínimo de 2ha (dois hectares) e no máximo 3 (três) unidades habitacionais por gleba (DISTRITO FEDERAL, 2012).
} 
relação de contraste com a realidade de concepção arquitetônica a partir de ecotécnicas (SATTLER, 2007) ${ }^{6}$ presenciada nos assentamentos rurais em formação no Distrito Federal.

\subsection{Objetivos}

Este artigo pretende apresentar o atual cenário de inter-relação entre as políticas públicas brasileiras de financiamento habitacional no campo e a realidade de implementação de construções mais sustentáveis em assentamentos rurais em formação no contexto do Distrito Federal do Brasil.

\section{Desenvolvimento}

\subsection{Procedimentos Metodológicos}

Para o desenvolvimento deste artigo, contou-se com o material produzido na experiência com a Prática de Escritório Modelo de Arquitetura e Urbanismo - PEMAU, disciplina desenvolvida no âmbito do Curso de Arquitetura e Urbanismo da Universidade de Brasília. O PEMAU - contou com de cerca de 30 integrantes, dentre alunos, professores e estagiário docente de doutorado.

Num primeiro momento, partiu-se para vivências, com visitas a centros de permacultura e a assentamentos rurais em formação no Distrito Federal e entorno.

Num segundo momento, organizou-se reuniões com a Comunidade Renascer e com o INCRA, além de workshops e palestras, no intuito de alcançar bases referenciais para a sugestão de projetos urbanísticos e arquitetônicos adequados para o Renascer.

Posteriormente, elaborou-se documentos de referência. As atividades de PEMAU resultaram na concepção de três cadernos-documento: o conteúdo destes inclui, além da síntese referencial pesquisada sobre temas de interesse relativos à habitação e urbanização rural, a documentação de visitas de campo aos

\footnotetext{
60 termo refere-se ao "conjunto de intervenções tecnológicas no ambiente que se baseia na compreensão dos processos naturais e tem como foco a resolução de problemas com o menor custo energético possível e com uso eficiente de bens naturais" (BRASIL, 2012).
}

assentamentos Pequeno William, Colônia I e Oziel Alves III - localizados no DF e entorno.

Em outra etapa, elaborou-se quatro propostas com projetos de urbanização para a área destinada à Comunidade; as propostas foram desenvolvidas em processo participativo com membros do Renascer pelos alunos de PEMAU. Além da elaboração de proposições urbanísticas destinadas à Comunidade Renascer, as atividades conduzidas no grupo de PEMAU resultaram em levantamentos de dados, resultados e conclusões relativos aos programas governamentais de financiamento habitacional no Brasil - dados que, acredita-se, ser de interesse de todas as comunidades rurais interessadas no financiamento de moradia e das demais instituições interessadas no desenvolvimento da arquitetura de interesse social no campo.

Num último momento, da definição de materiais para a construção das casas, detectou-se a grande limitação estabelecida pelos mecanismos de compras, que, embora os moradores desejem uma construção mais sustentável, são levados a compra de materiais convencionais. Durante o artigo, discutiremos esta problemática.

\subsection{O Programa Nacional de Habitação Rural - PNHR}

A problemática da distribuição fundiária no Brasil tem suas raízes cultivadas desde o período colonial, com a criação de capitanias hereditárias e sistema de sesmarias pela Coroa portuguesa no território nacional em 1530. Contudo, o histórico legislativo de luta pela reforma agrária no Brasil data de 1964, com a edição do Estatuto da Terra (Lei no 4.504, de 1964) e com a criação do Instituto Brasileiro de Reforma Agrária (Ibra) e do Instituto Nacional de Desenvolvimento Agrário (Inda) posteriormente fundidos na criação do INCRA, em 1970 - no início da ditadura militar no país.

O Estatuto da Terra, apesar de contribuir para o desenvolvimento de bases legislativas dentro do processo de reforma agrária no Brasil, acabou por desdobrar-se em um cenário de maior concentração de terras nas mãos de 
latifundiários no país, por conta de seu caráter impulsionador do capitalismo no campo, acompanhando a modernização da produção rural brasileira que caracterizou a década de 1960 (TEIXEIRA, 2005). Com a redemocratização do país, em 1984, a questão fundiária voltou à tona no Brasil, principalmente com a ascensão do Movimento dos Trabalhadores Rurais sem Terra (MST). A criação de novas políticas públicas de reforma agrária acompanhou o crescimento do MST e o surgimento de uma nova categoria dentro do meio de habitação coletiva no campo: o assentamento rural. Atualmente existem no Brasil 9.156 assentamentos rurais, ocupando uma área de 88.102.902ha. No Distrito Federal e Entorno, 13.053 famílias - 5.108 delas beneficiadas pelo programa Bolsa Família distribuem-se em 204 assentamentos (128 deles existentes há mais de 10 anos) ocupando uma área de 528.984,31ha (INCRA, 2014).

Em adição às iniciativas de reforma agrária que vêm sendo promovidas pela União nas últimas décadas, o Programa Minha Casa Minha Vida PMCMV -, de legislação promulgada em 2009 (BRASIL, 2009a), vem fortalecendo o desenvolvimento da qualidade habitacional e produtiva das comunidades rurais assentadas no território brasileiro.
O presente artigo se insere no contexto do PNHR - também conhecido como "Minha Casa Minha Vida Rural" -, regulamentado em 2009 (BRASIL, 2009b) com o objetivo de reduzir o déficit habitacional rural. O público-alvo inicial do Programa era representado por famílias de renda mensal de até 3 salários mínimos; atualmente, o PNHR atende a três grupos de beneficiários de acordo com a renda familiar anual: (i) até $R \$ 10.000,00$; (ii) de $R \$ 10.000,00 \mathrm{a}$ $\mathrm{R} \$ 22.000,00$; (ii) de $\mathrm{R} \$ 22.000,00 \quad \mathrm{a}$ $\mathrm{R} \$ 60.000,00$ - cada um dos três grupos beneficiados é contemplado por requisitos de contrapartida específicos; além disso, os grupos de beneficiários devem contar com no mínimo quatro e no máximo 50 famílias participantes.

A meta inicial do PNHR, em 2009, era de alcançar a marca de construção de 60 mil unidades contratadas no território nacional de acordo com o déficit habitacional de cada região brasileira. Em 2011, a meta foi alterada para 120 mil habitações até o final de 2014 (ver Tabela 01). A estimativa é que, até o final de 2015, 200 mil unidades sejam contratadas pelo PNHR; até o início de 2015, mais de 60 mil unidades já foram entregues pelo país - ver Tabela 02 (fonte: Agência de Notícias da Caixa Econômica Federal).

Tabela 1: Comparativo de metas e realizações do PNHR até o 20 semestre de 2013.

\begin{tabular}{lllllll}
\hline Região & $\begin{array}{l}\text { Déficit } \\
\text { Habitacional } \\
\text { (\%) }\end{array}$ & $\begin{array}{l}\text { Meta } \\
\text { contratações }\end{array}$ & $\begin{array}{l}\text { Meta } \\
\text { contratações } \\
\mathbf{2 0 0 9}\end{array}$ & $\begin{array}{l}\text { Contratos } \\
\text { realizados } \\
\mathbf{( 2 0 / 2 0 1 3 )}\end{array}$ & $\begin{array}{l}\text { Percentual } \\
\text { atingido/ } \\
\text { Meta 2009 }\end{array}$ & $\begin{array}{l}\text { Percentual } \\
\text { atingido/ } \\
\text { Meta 2011 }\end{array}$ \\
\hline Centro-Oeste & 3,23 & 2.735 & 5.470 & 3.604 & $131,78 \%$ & $65,89 \%$ \\
Nordeste & 69,95 & 39.402 & 78.804 & 23.488 & $59,60 \%$ & $29,80 \%$ \\
Norte & 11,68 & 7.803 & 15.606 & 10.949 & $140,32 \%$ & $70,16 \%$ \\
Sudeste & 8,39 & 5.509 & 11.018 & 13.935 & $252,94 \%$ & $126,47 \%$ \\
Sul & 6,74 & 4.551 & 9.102 & 34.783 & $764,30 \%$ & $382,15 \%$ \\
Brasil & 100 & 60.000 & 120.000 & 86.759 & $144,60 \%$ & $72,30 \%$ \\
\hline
\end{tabular}

Tabela 2: Relação de unidades entregues pelo PNHR até dezembro de 2014.

\begin{tabular}{lllllll}
\hline Região & Centro-Oeste & Nordeste & Norte & Sudeste & Sul & Brasil \\
\hline Unid. Entregues & 1.359 & 14.526 & 6.202 & 9.846 & 31.106 & 63.039 \\
\hline Fonte: Caixa, 2014. & & & & &
\end{tabular}

Dentro do PNHR, O Ministério das Cidades atua como gestor da aplicação dos recursos; o Ministério da Fazenda, por sua vez, é responsável pelo repasse de recursos à Caixa Econômica Federal - CEF e ao Banco do Brasil
- BB, instituições que liberam os recursos para a construção de empreendimentos e acompanham as obras, além de serem responsáveis pela análise e aprovação dos projetos de arquitetura das unidades 
habitacionais. Cabe à Caixa e ao BB aprovar ou não o financiamento de projetos em suas técnicas e materiais de acordo com os requisitos projetuais e especificações técnicas mínimas estabelecidos pelo Ministério das Cidades $^{7}$. Além disso, como canal de comunicação entre as instituições liberadoras de recursos e as comunidades beneficiadas, deve existir uma Entidade Organizadora (pessoa jurídica sem fins lucrativos, associações, cooperativas, sindicatos, poder público, prefeitura municipal, governo estadual ou do Distrito Federal) que elabore e apresente o projeto arquitetural e execute o trabalho social dentro da comunidade, que é pré-requisito para aceitação no Programa.

Os requisitos mínimos, materiais e técnicas construtivas estabelecidos pelo Ministério das Cidades (e aprovados pela Caixa Econômica Federal e pelo Banco do Brasil), no entanto, tendem a geralmente não corresponder às necessidades reais das famílias de assentamentos rurais interessadas em financiamento habitacional. Recentes estudos de caso em comunidades contempladas pelo PNHR no Brasil indicam que o valor liberado às famílias para a construção (de no máximo $\mathrm{R} \$ 28.500,00$ ) ou reforma (de no máximo $\mathrm{R} \$ 17.200,00)$ de unidades habitacionais, não contando com os apoios à Assistência Técnica $(R \$ 600,00)$ e ao Trabalho Social $(R \$ 400,00)$, é insuficiente para a execução das obras (GOMES, 2002).

\subsection{Ecotécnicas e as Unidades Habitacionais Rurais}

A sustentabilidade na construção civil se apoia no incentivo do uso de materiais mais ecológicos. Neste sentido, a utilização de materiais de cunho ecológico - em contraste com os materiais tradicionais de construção civil empregados nos recentes empreendimentos do PMCMV - na construção de edificações mais sustentáveis apresenta-se como uma necessidade latente dentro do contexto dos assentamentos rurais brasileiros em formação,

\footnotetext{
7 Documento disponível no endereço eletrônico: $<$ http://www.cidades.gov.br/images/stories/Arquivos SNH/ArquivosPDF/Especificacoes_Minimas_PNHR.pdf>
}

tanto por fatores ambientais quanto culturais. Porém, os processos de certificação de ecoprodutos (SILVA, 2012)8 para aprovação pelos agentes financiadores do PMCMV delegados ao Programa Brasileiro de Qualidade e Produtividade do Habitat (PBQP-H) - podem apresentar-se lentos e excessivamente burocráticos; desta maneira, as limitações que o financiamento da arquitetura de interesse social no campo impõem à construção de unidades de habitação mais sustentáveis entra em conflito com a realidade de urgente necessidade por moradia de qualidade que é enfrentada pelas famílias de assentamentos rurais. Considerando este cenário, cabe, portanto, a investigação: estarão as vigentes políticas públicas habitacionais para o campo sustentadas pelo PNHR efetivamente alcançando seu públicoalvo e atingindo suas diretrizes normativas de compatibilidade das propostas arquitetônicas com características regionais e climáticas e de atendimento a projetos que contemplem parâmetros de sustentabilidade ambiental ${ }^{9}$ ?

\subsection{A busca por construções mais sustentáveis}

É amplamente divulgado no meio acadêmico atual que o setor da construção civil figura como um dos grandes responsáveis pela crise ambiental mundial. Este cenário tende a se agravar num futuro próximo devido, principalmente, ao crescimento do setor nos países em desenvolvimento. Tal é o caso do Brasil: embora esteja o país enfrentando um período de estagnação no segmento em 2015, o setor tem apresentado um crescimento expressivo nos últimos anos, segundo estimativa do Sindicato da Indústria da

\footnotetext{
${ }^{8}$ Silva (2012) argumenta que ecoprodutos, "materiais e tecnologias ambientalmente corretos e saudáveis", se distinguem de produtos convencionais por conta do fator "desempenho sustentável". Ecoprodutos devem, portanto, suprir especificações técnicas de materiais convencionais, sendo regulados por normas técnicas e testados em sua eficiência.

9 "Art. 2o - Constituem diretrizes do PNHR: (...) II - os projetos arquitetônicos deverão apresentar compatibilidade com as características regionais, locais, climáticas e culturais da localidade, e ainda prever a ampliação futura da unidade habitacional; (...) IX atendimento a projetos que contemplem parâmetros de sustentabilidade ambiental; (...)" (BRASIL, 2013).
} 
Construção Civil do Estado de São Paulo (MACIEL, 2014). Isso se deve, em grande medida, à ação do Estado em programas como - Programa de Aceleração do Crescimento (PAC) e o PMCMV (LISBOA, 2014). Fica evidente, portanto, a necessidade de se modificar a prática construtiva tradicional por opções mais sustentáveis no contexto brasileiro, bem como o importante papel que o Estado cumpre neste processo.

Sattler (2007), ao invés de pretender fornecer a palavra final em termos de uma construção sustentável, defende a adoção do termo "edificações mais sustentáveis" ${ }^{\text {". Tal visão }}$ implica em uma percepção do caráter progressivo da busca pela sustentabilidade nas edificações e do fato de ainda estarmos iniciando um longo processo em busca desse ideal.

Uma importante ferramenta para a avaliação de uma prática construtiva sustentável consiste na Análise de Ciclo de Vida (ACV) aplicada aos materiais construtivos utilizados ${ }^{11}$. Para a sua determinação são considerados os insumos (energéticos ou materiais) necessários e as emissões implicadas para a produção e uso dos materiais envolvidos (SILVA, 2012). Porém, deve-se destacar a complexidade envolvida numa avaliação deste tipo, a qual envolve dados diversificados e de difícil acesso e avaliação. Não por acaso, desde o final dos anos 70 presenciou-se 0 surgimento de múltiplas metodologias de ACV, sem que se tenha, até hoje, chegado a um consenso sobre a questão (SILVA, 2012, p. 46-52). No âmbito da construção civil brasileira, é recomendado que os estudos de ACV sigam princípios e estruturas estabelecidos nas normas da família NBR ISO 14040 (BUENO, 2010), em adição às normas de desempenho de edificações

\footnotetext{
10 "Ser mais sustentável" pode ser entendido de maneira genérica como viver dentro da capacidade de suporte do platena. No âmbito da construção civil, Sattler (2007) defende que o termo implica na utilização de materiais endêmicos, de baixo consumo energético e de reduzida geração de resíduos (sólidos, líquidos e gasosos) em seu ciclo de uso e produção.

${ }^{11}$ Sattler (2007) enumera uma série de trabalhos nos quais são utilizados os conceitos de ACV na avaliação de produtos da construção civil.
}

estabelecidas pela NBR 15575 - que dispõe sobre 0 desempenho de edificações habitacionais de até cinco pavimentos - e pela NBR 15220 - que discorre sobre o desempenho térmico de edificações.

Além disso, como salienta Silva (2012), também os critérios de desempenho e durabilidade de ecoprodutos devem ser considerados para se avaliar sua real sustentabilidade. Se seu desempenho for insatisfatório ou se sua vida útil for demasiado curta - sendo necessários reposições ou reparos constantes - é possível que a utilização de um potencial ecoproduto acabe acarretando em impactos semelhantes ou superiores ao uso de materiais tradicionais. Deve-se observar também que o conceito de sustentabilidade não se restringe apenas à dimensão ambiental, de forma que os aspectos culturais, sociais, econômicos e políticos do local de intervenção envolvidos no processo construtivo devem ser igualmente levados em consideração para se almejar edificações mais sustentáveis (SATTLER, 2007).

\subsection{Problemas enfrentados pelas comunidades na produção de habitações mais sustentáveis}

Os estudos de caso realizados pelo grupo de PEMAU no Distrito Federal reafirmam os trabalhos que constatam a inconformidade dos padrões das unidades do PNHR com os modos de vida e construções tradicionais de assentamentos rurais distribuídos pelo Brasil, além dos valores culturais (SILVA, 2014).

As visitas de campo aos assentamentos Pequeno William, Colônia I e Oziel Alves III cada um deles apresentando estágios diferentes de organização social e situação de urbanização - desdobraram-se em constatações distintas acerca da opinião popular sobre os materiais e técnicas construtivas presentes nas unidades do PMCMV. O assentamento Pequeno William, localizado na região administrativa de Planaltina - DF e baseado na produção orgânica e agroecológica, é composto atualmente por 22 famílias distribuídas em cinco núcleos de moradia, sendo que cada família possui em 
média 5,5ha de terra. A urbanização da região já se encontra em estágio avançado, contando com energia elétrica, água potável, saneamento básico completo e reservatório de água para irrigação e consumo. Um dos fatores que distinguem 0 Pequeno William dentro dos assentamentos do DF é o desenho urbano aplicado ao território: projetado em processo participativo com a comunidade e com 0 INCRA, ele divide os cinco núcleos de famílias seguindo critérios de afinidade; além disso, cada núcleo conta com um pequeno centro comunitário, e as unidades habitacionais são dispostas próximas umas das outras: estratégias como essas impedem a dispersão das famílias da unidade comunitária e fortalecem os laços produtivos e sociais. Dentro desse cenário, os habitantes do Pequeno William encontram-se atualmente contemplados por um equipamento urbano e social de qualidade; em contrapartida, sofrem com a falta de recursos para a construção de moradias adequadas. $\mathrm{O}$ agricultor Gaspar Araújo relatou ao grupo de PEMAU, quando questionado se recorreria ao PNHR para o financiamento habitacional, que muitas famílias - incluindo a dele - não teriam seu modo de vida contemplado pelas unidades-padrão do PMCMV; algumas comunidades de outros assentamentos, inclusive, aceitaram 0 financiamento e construíram suas casas em conformidade com os padrões construtivos (utilizando de concreto armado e alvenaria) aprovados pelo Programa, mas nunca chegaram a habitar as unidades construídas algumas famílias relataram sentir desconforto térmico dentro das unidades; outras se queixaram do tamanho reduzido de cômodos. Sem o recurso do PMCMV, porém, Gaspar e as outras famílias de seu núcleo comunitário não conseguiram, até o momento da entrevista, construir uma unidade habitacional para sua família - segundo o agricultor, sua casa ideal deveria "ser construída com tijolos de adobe produzidos no assentamento e contar com uma grande varanda para ver passar o tempo".

Figura 1(a,b,c): Unidade de habitação, tijolos de adobe produzidos artesanalmente e divisão de terras realizada em processo participativo no assentamento Pequeno William.
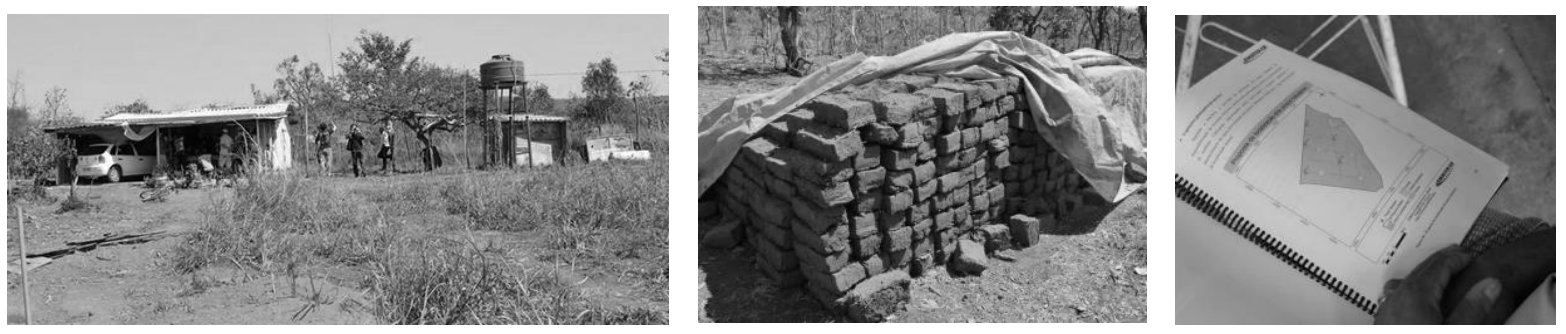

Fonte: CASAS, 2014.

O assentamento Colônia I, por sua vez, é estruturado de maneira distinta; localizado em Padre Bernardo, em Goiás, ele conta com 24 unidades produtivas que não apresentam grande coesão comunitária: as famílias não moram próximas umas às outras, e nem todas estão inseridas em grupos produtivos. 0 Colônia I, porém, foi bem-sucedido na produção agroecológica. Em visita de campo, o grupo de PEMAU pode constatar o caráter cultural que a arquitetura baseada em ecotécnicas representa para os membros da comunidade. A família do agricultor entrevistado Wátila José dos Santos construiu recentemente, sem o auxílio do PNHR, habitação e unidades anexas utilizando da técnica de hiperadobe. Satisfeito com o conforto ambiental proporcionado pela construção, com a segurança do ecoproduto e com o tamanho da habitação construída, o agricultor relatou que não recorreria às unidades do PMCMV; entretanto, admitiu que são poucas as famílias que têm acesso a recursos suficientes para construírem habitações adequadas nos assentamentos rurais da região. 
Figura 2(a,b,c): Habitação construída em hiperadobe no assentamento Colônia I.
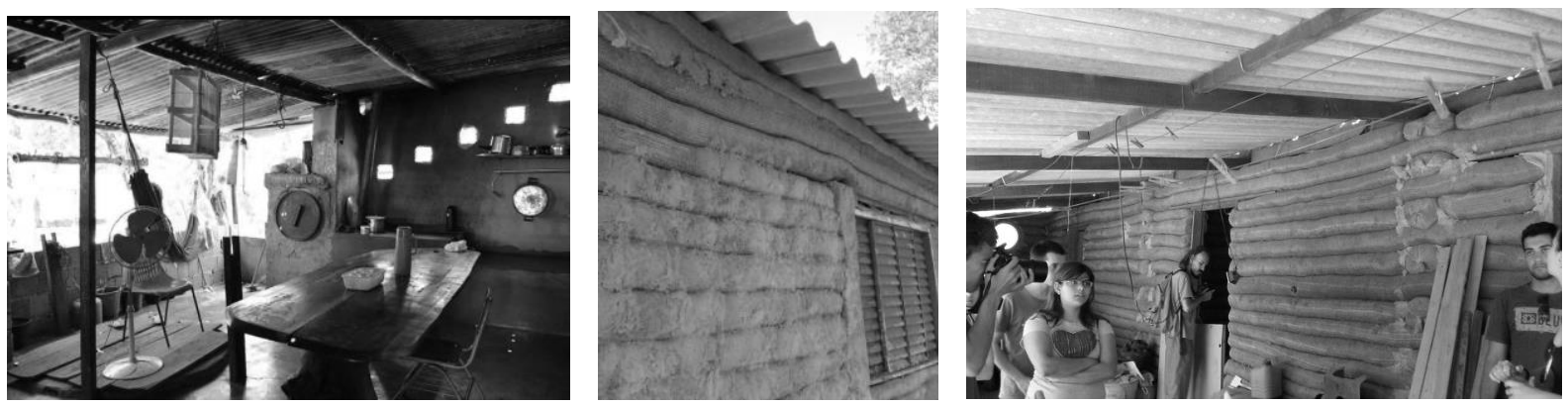

Fonte: CASAS, 2014.

O assentamento Oziel Alves III, situado na região de Planaltina - DF, conta com a presença de 168 famílias. Assim como no Pequeno William, o desenho urbano da área foi moldado em processo participativo, em terrenos dispostos em agrupamentos de 16 núcleos produtivos (contando também com 9 áreas comunitárias) com moradias dispostas próximas umas às outras e unidades de área variando entre 5 e 9 hectares. $O$ assentamento atualmente recebe obras de urbanização na área apropriada, que se encontra devastada pela monocultura e localiza-se isolada no que diz respeito ao acesso à água potável; apesar disso, a comunidade em geral não busca a produção agroecológica. No que diz respeito às unidades habitacionais, parte da comunidade do Oziel Alves III está disposta, desde 2013, a se inscrever no PMCMV, diferente da realidade presenciada nos assentamentos Pequeno William, Colônia I e Renascer.

Em suma, a pesquisa em estudos de caso apontou para a realidade expressiva de busca pela construção de unidades habitacionais mais sustentáveis seguindo ecotécnicas e utilizandose de ecoprodutos, respeitando a identidade cultural local, os fatores ambientais endêmicos e a possibilidade de autoconstrução por parte das famílias nos assentamentos rurais em formação no DF, independente da forma de organização da produção agrícola local.
Figura

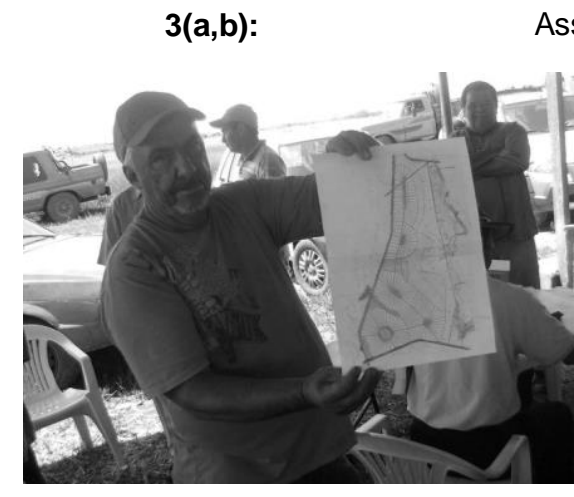

Fonte: CASAS, 2014

Tomadas as considerações acerca da busca pela sustentabilidade das edificações, verificase que o desejo expressado por muitas famílias de assentamentos rurais de construir moradias de características construtivas partindo de ecoprodutos enfrenta dois grandes obstáculos: o primeiro é relacionado à discrepância de identidade entre as unidades financiadas pelo PMCMV e as habitações mais sustentáveis
Assentamento Oziel

III.

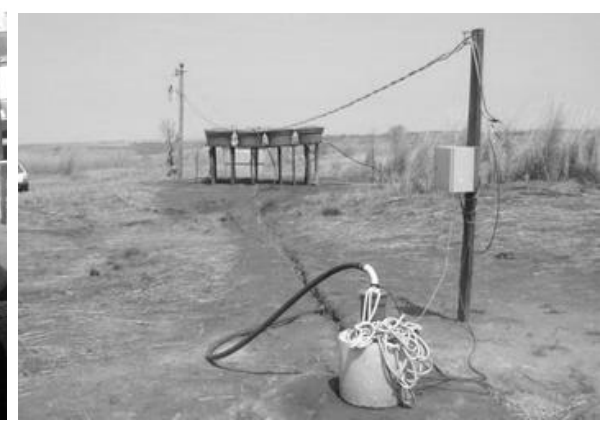

desejadas pelas famílias; o segundo refere-se à falta de bases e assistência técnicas que permitam a construção de unidades mais sustentáveis que sejam construtivamente seguras. Os dois problemas estão intrinsecamente relacionados, uma vez que a aprovação de produtos alternativos dentro do PMCMV depende também da comprovação da eficiência de ecoprodutos por meio da utilização destes em obras concluídas e bem-sucedidas; 
sem assistência técnica, muitas construções utilizando ecotécnicas são fadadas ao fracasso, o que atesta contra a adoção de materiais mais sustentáveis no Programa Minha Casa Minha Vida e afasta a possibilidade de financiamento de habitações rurais mais sustentáveis em assentamentos distribuídos no território brasileiro. Esta realidade de insucesso construtivo foi evidenciada por Ino e Maia (2010) dentro do assentamento rural Sepé Tiaraju, localizado em Serra Azul, São Paulo, a partir de experimento conduzido pelo Grupo de Pesquisa em Habitação e Sustentabilidade (Habis), do Instituto de Arquitetura e Urbanismo da Universidade de São Paulo - IAU/USP, em parceria com $\circ$ Departamento de Engenharia Civil Universidade Federal de São Carlos DeCiv/UFSCar.

Neste cenário, é preciso salientar a grande importância da certificação de desempenho mecânico de materiais alternativos por órgãos reconhecidos para o reconhecimento destes no âmbito do PMCMV. Atualmente, os processos de certificação de materiais são delegados ao Sistema Nacional de Avaliações Técnicas de Produtos Inovadores (SINAT), criado dentro do âmbito do Programa Brasileiro de Qualidade e Produtividade do Habitat (PBQP-H).

\subsection{Qualidade da Habitação: o PBQP-H e o SINAT}

As conferências Habitat surgidas no âmbito da UN-Habitat, colocaram em discussão a crise urbana que caracterizou o século $X X$, com a crescente e desordenada urbanização e consequentes problemas sociais e de moradia, principalmente nos países em desenvolvimento. Antonucci et al. (2009) apontam para uma mudança de estratégia de ação da primeira para a segunda conferência: se em Vancouver - Estado (a partir de uma perspectiva ainda keynesiana) foi tratado como protagonista e único agente capaz de resolução dos problemas de moradia e urbanização; em Istambul ênfase foi dada à ação descentralizadora de diversos elementos não-governamentais, à participação da sociedade civil e a parcerias com o setor privado (ANTONUCCl et al., 2009).
Como resposta aos compromissos firmados na Habitat II e à situação de déficit habitacional que é evidenciada de modo expressivo no Brasil12, foi criado, em 1998, o Programa Brasileiro de Qualidade e Produtividade do Habitat- PBQP-H (BRASIL, 1998)13. Visando a modernização produtiva e a melhora da qualidade das moradias no Brasil, o programa se propõe a um conjunto de ações e objetivos específicos, a saber:

Avaliação da conformidade de empresas de serviços e obras, melhoria da qualidade de materiais, formação e requalificação de mão-de-obra, normalização técnica, capacitação de laboratórios, avaliação de tecnologias inovadoras, informação ao consumidor e promoção da comunicação entre os setores envolvidos (BRASIL. Ministério das Cidades, O PBQP-H Apresentação, s/d).

Por meio dessas ações, portanto, o programa busca melhorar as condições produtivas na construção civil, reduzindo custos e otimizando gastos públicos a fim de se reduzir o déficit de habitação no Brasil - atendendo, primordialmente, às habitações de interesse social, segundo o Ministério das Cidades.

Em 2007, foi instituído, no âmbito do PBQP-H, o Sistema Nacional de Avaliações Técnicas de Produtos Inovadores - SINAT. O objetivo do sistema é de avaliar novos produtos da construção civil que possibilitem melhoria na qualidade e produtividade do habitat e que ainda não possuam norma técnica específica, possibilitando o fornecimento de condições para o desenvolvimento tecnológico na construção civil. Nesse sentido, surge como uma boa

\footnotetext{
${ }^{12}$ Segundo estudo do IPEA (GONÇALVES, 1999, p.4), o déficit habitacional brasileiro atingia 5.408 .934 de domicílios em 1996, uma marca relativa de $13,6 \%$ do total de unidades habitacionais do país. Segundo estimativa da Fundação João Pinheiro (2014), o déficit habitacional no Brasil em 2012 atingiu a marca de 5.792.508 unidades (marca relativa de 9,1\%), apresentando leve melhora em relação ao quadro de 2007 - que apresentou marca relativa de 10,8\%.

13 Originalmente, era conhecido como Programa Brasileiro da Qualidade e Produtividade na Construção Habitacional, tendo seu nome mudado em 2000 a fim de se englobar também as áreas de saneamento e infraestrutura urbana.
} 
oportunidade para a qualificação, normalização e popularização dos ecoprodutos e ecotécnicas.

Vinculado à Secretaria Nacional de Habitação do Ministério das Cidades, o SINAT estrutura-se em Secretaria Geral, Comissão Nacional, Comitê Técnico e em diversas Instituições Técnicas Avaliadoras (ITAs). Assim, caracteriza-se por abranger, em seus componentes, as esferas pública e privada, contando com representantes diversos: governamentais e agentes financiadores públicos e promotores da habitação, membros da cadeia produtiva da construção civil (fabricantes, incorporadoras e empresas de engenharia e arquitetura) e instituições de pesquisa e ensino, além dos consumidores de produtos da construção civil.

Já as Instituições Técnicas Avaliadoras (ITAs) são entidades independentes que cumprem o papel de analisar tecnicamente, em diversas etapas, tecnologias inovadoras- enviadas para avaliação por proponentes interessados na normatização de produtos. Com o processo de análise, as ITAs elaboram minutas de Diretrizes SINAT e DATecs.

DATec consiste em documento que expressa a opinião do SINAT sobre o desempenho potencial ou provável de um produto inovador, avaliando seu uso, instalação, execução, operação, manutenção, etc. Tem como finalidade divulgar aos profissionais da construção civil informações sobre as características técnicas e sobre o desempenho provável de produtos que não possuem norma técnica específica ou que não estejam amparados pelo conhecimento construtivo tradicional. Assim, com base no conteúdo de um DATec, os profissionais podem balizar-se tecnicamente para o uso de novos produtos e processos.

Deve-se lembrar, porém, que um DATec não oferece garantias da parte de qualquer uma dos integrantes do SINAT e não isenta o usuário, o proponente, o produtor e o comerciante do produto de suas respectivas responsabilidades (BRASIL, 2007).
O grande benefício do DATec consiste em facilitar a concessão de crédito de financiadores públicos em programas do governo como o PMCMV (a existência de um DATec não constitui, no entanto, prerrogativa para 0 financiamento público - o documento funciona como atestado confiável de desempenho de produtos, facilitando o processo de liberação de recursos). Para consegui-lo é necessário um longo processo burocrático, descrito brevemente a seguir.

\subsubsection{O processo de obtenção de DATecs}

Relações iniciais são estabelecidas entre o Proponente de um produto/processo inovador e uma ITA, que deve fazer uma análise preliminar para saber se o produto já é ou não alvo de um DATec. A partir dessa avaliação preliminar, a ITA emite uma Proposta de Trabalho ao Proponente, na qual considerara a viabilidade de concessão de DATec, a documentação técnica disponível para o produto, e todos os passos do processo burocrático de obtenção de um DATec, iniciado com a aceitação da Proposta de Trabalho pelo Proponente.

$\mathrm{Na}$ ausência de uma Diretriz, no âmbito do SINAT, que já contenha as bases de avaliação da classe do produto em questão, a ITA elabora uma Minuta de Diretriz SINAT, cuja versão final será redigida por um comitê técnico específico, referendada e, então, publicada.

A partir dessa Diretriz, é dado seguimento à avaliação técnica do produto/processo, que resulta em um Relatório Técnico de Avaliação (RTA - de acesso restrito). Em caso de resultado negativo no RTA, o Proponente pode realizar ajustes para retomar a avaliação técnica. Se o resultado for positivo, a ITA deve averiguar se o Proponente possui condições de controle de qualidade nos processos de produção e de orientação técnica ao mercado.

Caso essa averiguação seja também positiva, a ITA elabora uma Minuta de DATec e a encaminha para apreciação de Comitê Técnico. Caso este considere a Minuta adequada, deve encaminhá-la aos demais membros para que seja feita apreciação e concessão da chancela SINAT ao DATec - que, enfim, pode ser 
publicada pela ITA.

A ITA deve propor, na Minuta de DATec, a periodicidade de auditorias técnicas de controle do produto após a concessão de DATec, bem como ajustar com o Proponente as condições de realização do controle periódico do produto/processo.

O DATec tem validade de dois anos, podendo ser renovado por igual período em caso de interesse do Proponente, se não houver alteração do produto e se este estiver de acordo com a avaliação periódica. O DATec também pode ser revogado em caso de não cumprimento das condições de concessão definidas no regimento do SINAT, ou se houver alteração do produto sem avaliação, ou ainda se o desempenho do produto for identificado como insatisfatório.

\subsubsection{Avaliação das novas tecnologias}

No site do Ministério das Cidades é possível consultar uma lista ${ }^{14}$ na qual constam todas as Diretrizes e DATec's aprovadas até hoje pelo SINAT. Observa-se que os produtos/processos inovadores que até agora receberam a chancela do Sistema consistem, em sua maioria, em sistemas construtivos que se utilizam de materiais tradicionais, como o concreto, o aço e blocos cerâmicos.

Ou seja, a inovação até agora chancelada pelo SINAT diz respeito, quase que exclusivamente, a processos construtivos inovadores; são raros os casos de novos materiais, principalmente produtos de menor impacto energético e residual na sua cadeia de produção, conforme se pode observar no gráfico ${ }^{15}$ a seguir:

\footnotetext{
$14 \quad$ Disponível em: <http://pbqph.cidades.gov.br/projetos_sinat.php> Acesso em 3 março 2015.

150 gráfico engloba todos os DATec's já aprovados, incluindo-se aqueles que já venceram ou que, por algum motivo, foram revogados. Sistemas construtivos que se utilizam de mais de um material tiveram seus componentes contados separadamente.
}

Gráfico 1: Materiais utilizados em DATecs aprovados pelo SINAT.

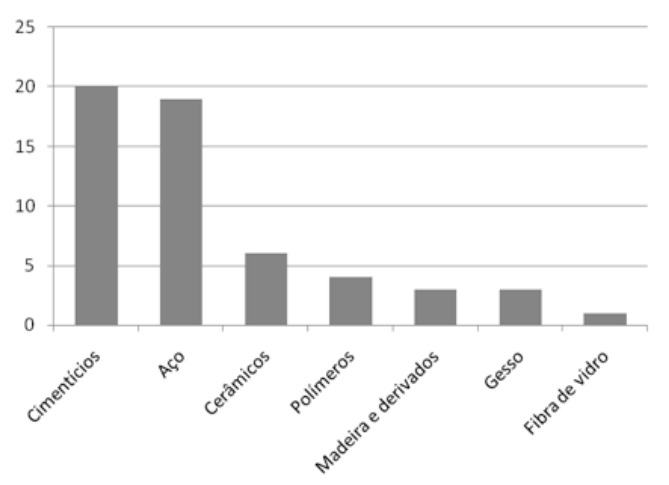

Fonte: PBQP-H, 2014.

Deste modo, observa-se que os processos/produtos inovadores que alcançaram a chancela SINAT não estão comprometidos com a adoção de práticas mais sustentáveis na construção civil - ao menos não em todas as suas dimensões. De fato, no que tange às vedações verticais, que compõem a maioria dos produtos-alvo de DATecs, houve avaliação (baseada na NBR 15220) do desempenho térmico dos produtos na maioria dos casos. No entanto, isto não significa que todos apresentem bom desempenho nas diversas zonas bioclimáticas brasileiras. Em algumas ocasiões, inclusive, admitiu-se um desempenho aceitável bastante restrito a algumas condições ${ }^{16}$, como o uso de cores claras, presença de ventilação e sombreamento - situação nem sempre encontradas nos empreendimentos de habitação social no Brasil.

Outros ensaios realizados pelas ITAs verificaram 0 desempenho acústico, estanqueidade à água, compressão excêntrica e estanqueidade ao fogo, durabilidade e manuseabilidade de materiais, partindo de critérios estabelecidos na Diretriz SINAT para classes específicas de produtos ou parcialmente na NBR $15575^{17}$. Porém, não são observados ensaios de avaliação específica de

\footnotetext{
${ }^{16}$ É o caso dos sistemas construtivos alvos dos DATecs no 15,16 e 20 .

17 O engenheiro José Sergio dos Passos Oliveira, membrodo Ministério das Cidades, informou ao grupo de PEMAU em 2014 que encontra-se em fase final um processo para adequação das Diretrizes SINAT à Norma de Desempenho NBR 15575.
} 
Análise de Ciclo de Vida (ACV) dos materiais, considerando os insumos energéticos e resíduos implicados no ciclo de vida dos produtos analisados (deve-se, porém, reconhecer a dificuldade de avaliações deste tipo, conforme mencionado anteriormente; além disso, a realização de ACVs pelas ITAs implicaria em aumentos sobre o custo e o tempo do processo de avaliação dos produtos).

Outro fator que deve ser destacado diz respeito à origem dos proponentes de produtos aprovados pelo SINAT: todos são representados por empresas do ramo da construção civil. Não há, no levantamento realizado, ocorrência de instituições de pesquisa como proponentes, por exemplo. Essa situação pode estar relacionada à dificuldade de se cumprir o procedimento técnico e burocrático para se conseguir um DATec. Com efeito, o pesquisador do Instituto de Pesquisas Tecnológicas Sérgio Angulo (apud SILVA, 2012, p. 42) afirma que o processo de obtenção de um DATec envolve gastos consideráveis para a realização das avaliações técnicas, além de se estender por um longo período(em geral, de 2 a 3 anos). Considerando esses fatores, é possível compreender a ausência de pessoas e entidades que não exercem atividades lucrativas na área de construção civil (e que, portanto, não dispõem do capital necessário para investir no processo de recebimento de um DATec $)^{18}$ nas listas de Proponentes aprovados pelo SINAT. Dentro deste cenário, as comunidades rurais interessadas em financiamento habitacional encontram-se em situação muito debilitada. Uma vez que a inserção de ecoprodutos no mercado do Programa Minha Casa Minha Vida não tem sido de interesse das grandes empresas de construção civil, não parece haver iniciativa capaz de defender os interesses sociais percebidos na experiência de PEMAU com os assentamentos rurais - por uma habitação mais sustentável no âmbito do PBQP-H, programa criado para atender justamente às habitações

\footnotetext{
18 A falta de recursos é ressaltada pela pesquisadora Luciana Oliveira, também do Instituto de Pesquisas Tecnológicas, para explicar a dificuldade de realizar testes em ecoprodutos (SILVA, 2012, p. 44).
}

de interesse social.

\section{Conclusões}

O Brasil enfrenta problemas contraditórios relacionados ao ramo da construção civil: se, por um lado, deve-se considerar o grande déficit habitacional nacional, por outro, evidencia-se a necessidade de se buscar, de forma urgente, a sustentabilidade na construção civil em uma escala nacional, atendendo principalmente às comunidades que mais precisam de recursos básicos de habitação. Iniciativas governamentais como o PMCMV, além de programas como o PBQP-H e o SINAT, constituem-se como iniciativas de importância sem precedentes no sentido de melhorar a qualidade e produtividade na construção civil e o acesso à moradia no Brasil. Entretanto, tais programas, que figurariam como uma estratégia para um salto de qualidade na construção civil brasileira, apresentam entraves que têm comprometido melhoras efetivas no quadro da arquitetura de interesse social que se nota de forma mais enfática no campo e de busca pela inserção de tecnologias e materiais de construção mais sustentáveis.

Como exemplo de algumas iniciativas positivas nesse sentido, pode-se destacar uma recente portaria do Ministério das Cidades, que passa a permitir o uso de madeira em empreendimentos do PNHR, observados os planos de utilização da matéria-prima florestal do ICMBIO (BRASIL, 2014). Também é conveniente lembrar que, ao contrário do que se percebe na política habitacional atual, fortemente baseada na parceria com grandes empresas de construção civil (como visto, das inovações materiais à execução de obras), houve um momento ainda que lamentavelmente curto - em que a autoconstrução e o uso de materiais locais e sustentáveis foi parte de uma política habitacional de Estado. Trata-se do célebre exemplo do Cajueiro Seco, quando painéis préfabricados para taipa (a serem preenchidos com barro pelos próprios moradores) foram adotados na constituição de um bairro na região metropolitana do Recife, entre 1963 e 1964 (SOUZA, 2008).

Dentro do contexto burocrático de aprovação 
dessas tecnologias e materiais, deve-se destacar o papel crucial que as universidades brasileiras - com seus laboratórios e canteiros experimentais - podem desempenhar, como ITAs, para a construção de empreendimentos de habitação social mais sustentáveis - papel que hoje se encontra renegado. O presente trabalho, por fim, faz um chamamento às universidades e aos universitários - sejam eles estudantes, professores ou pesquisadores para que invistam no desenvolvimento de seus canteiros experimentais e se atentem ao imenso potencial que possuem, enquanto instituições de ensino e de aprendizado, de aprovar técnicas, aproveitar oportunidades, expandir horizontes, quebrar cartéis e transformar, mesmo que lentamente, a realidade social no Brasil de maneira efetiva.

\section{Referências}

AGENDA HABITAT. Documento resultante da II Conferência das Nações Unidas para os Assentamentos Humanos. Istambul, 1996.

ANTONUCCI, D. et al. UN-Habitat: 3 décadas de atuação. Arquitextos, São Paulo, ano 09, n. 107.01, Vitruvius, abr. 2009.

BARONE, A. C. C.; DOBRY, S. A. "Arquitetura Participativa" na visão de Giancarlo de Carlo. Revista do Programa de Pós-graduação em Arquitetura e Urbanismo da Fauusp, São Paulo, n. 15, p. 18-31, 2004.

BRASIL. Portaria n. 134, de 18 de dezembro de 1998. Diário Oficial da União. Brasília, 19 dez. 1998.

Lei n. 11.977, de 7 de julho de 2009. Diário Oficial da União. Brasília, 8 jul. 2009a.

Portaria Interministerial n. 326 de

31 de agosto de 2009. Diário Oficial da União. Brasília, 1 abr. 2009b.

Ministério da Educação. Vamos

cuidar do Brasil com escolas sustentáveis: educando-nos para pensar e agir em tempos de mudanças socioambientais globais. Brasília, 2012.

BUENO, C. Avaliação de desempenho ambiental de edificações habitacionais: análise comparativa dos sistemas de certificação no contexto brasileiro. São Carlos: USP, 2010. 123f. Dissertação de Mestrado - Departamento de Arquitetura e Urbanismo da Escola de Engenharia de São Carlos, USP, 2010.

DISTRITO FEDERAL Lei Complementar ํㅜ 854, de 15 de outubro de 2012. Diário Oficial do Distrito Federal. Brasília, 17 out. 2012.

FAGUNDES, J. R.; CAMPIGOTTO, L.; ZONTA, P.; CETOLIN, S. F. Análise das metas do Programa Nacional de Habitação Rural (PNHR) no Contexto Nacional. Colóquio: Revista do Desenvolvimento Regional, Taquara/RS, v. 10, n. 2, 2013.

FUNDAÇÃO JOÃO PINHEIRO. Nota Técnica: Déficit Habitacional no Brasil - Anos 2011 e 2012. Belo Horizonte: Centro de Estatística e Informações, 2014.

GOMES, E. A agroecologia nos assentamentos de reforma agrária: o caso do assentamento Alvorada. XL Congresso Brasileiro de Economia e Sociologia Rural. RS, 2002.

GONÇALVES, Robson R. O déficit habitacional brasileiro: um mapeamento por unidades da federação e por níveis de renda domiciliar. Rio de Janeiro: IPEA, 1998.

GOUVÊA, I.; GOUVÊA, P. T. R. Profissão do Arquiteto na Sociedade Brasileira: avaliação e perspectivas. Revista da Faculdade de Engenharia, Arquitetura e Tecnologia da Universidade de Marília, São Paulo, v. 6, n. 1, p. 49-53, 2004.

KOUTZII, F. A Tragédia da Educação. Porto Alegre: Corag, 1993. 118 p.

LISBOA, V. Indústria da construção cresce 10,2\% de 2011 a 2012. Agência Brasil, Rio de Janeiro, 2014. Disponível em <http://agenciabrasil.ebc.com.br/economia/notici a/2014-09/industria-da-construcao-cresceu-102de-2011-para-2012-divulga-ibge $>$. Acesso em 4 mar. 2015.

MACIEL, C. Sindicato prevê estagnação do setor de construção civil em 2015. Agência 
Brasil, São Paulo, 2014. Disponível em: <http://agenciabrasil.ebc.com.br/geral/noticia/20 14-11/sindicato-preve-estagnacao-do-setor-deconstrucao-civil-em-2015>. Acesso em 4 mar. 2015.

MAIA, R. T.; AKEMI, I. Variáveis Técnicas que interferiram no uso da terra para habitação social. Caso: assentamento rural Sepé Tiaraju, Serra Azul-SP. III Congresso de Arquitetura e Construção com Terra no Brasil, Campo Grande/MS, 2010.

SATTLER, Miguel A. Ecoconstruções. In: ROMERO, Marta Adriana Bustos (Org.). Reabilitação Ambiental Sustentável Arquitetônica e Urbanística. Reabilita. Registro de Curso de Especialização a Distância. PPGFAU/UnB. Brasília, 2008.

SILVA, C. M. G. Habitação Rural: uma luta por cidadania. São Paulo: USP, 2014. 152f. Dissertação de Mestrado - Departamento de Arquitetura e Urbanismo da USP, 2014.

SILVA, J. C. S. Critérios para Seleção de Ecoprodutos: uma visão crítica acerca do emprego de materiais de construção sustentáveis no Brasil - o caso da madeira plástica. Rio de Janeiro: UFRJ, 2012. 116 f. Dissertação de Mestrado - Programa de Engenharia Urbana, Escola Politécnica, UFRJ, 2012.

TEIXEIRA, J. C. Modernização da Agricultura no Brasil: impactos econômicos, sociais e ambientais. Revista Eletrônica da Associação dos Geógrafos Brasileiros - Seção Três Lagoas, Três Lagoas/MS, v. 2, n. 2, setembro 2004. 